\title{
Metabolite analysis of endophytic fungi from cultivars of Zingiber officinale Rosc. identifies myriad of bioactive compounds including tyrosol
}

\author{
C. Anisha ${ }^{1}$ - E. K. Radhakrishnan ${ }^{1} \mathbb{C}$
}

Received: 5 October 2016/Accepted: 13 February 2017/Published online: 8 June 2017

(C) Springer-Verlag Berlin Heidelberg 2017

\begin{abstract}
Endophytic fungi associated with rhizomes of four cultivars of Zingiber officinale were identified by molecular and morphological methods and evaluated for their activity against soft rot pathogen Pythium myriotylum and clinical pathogens. The volatile bioactive metabolites produced by these isolates were identified by GC-MS analysis of the fungal crude extracts. Understanding of the metabolites produced by endophytes is also important in the context of raw consumption of ginger as medicine and spice. A total of fifteen isolates were identified from the four varieties studied. The various genera identified were Acremonium sp., Gliocladiopsis sp., Fusarium sp., Colletotrichum sp., Aspergillus sp., Phlebia sp., Earliella sp., and Pseudolagarobasidium sp. The endophytic community was unique to each variety, which could be due to the varying host genotype. Fungi from phylum Basidiomycota were identified for the first time from ginger. Seven isolates showed activity against Pythium, while only two showed antibacterial activity. The bioactive metabolites identified in the fungal crude extracts include tyrosol, benzene acetic acid, ergone, dehydromevalonic lactone, $\mathrm{N}$-aminopyrrolidine, and many bioactive fatty acids and their derivatives which included linoleic acid, oleic acid, myristic acid, $n$ hexadecanoic acid, palmitic acid methyl ester, and methyl linoleate. The presence of these varying bioactive endophytic fungi may be one of the reasons for the differences in the performance of the different ginger varieties.
\end{abstract}

E. K. Radhakrishnan

radhakrishnanek@mgu.ac.in

1 School of Biosciences, Mahatma Gandhi University, P D Hills, Kottayam, Kerala 686 560, India
Keywords Ginger · Endophytic fungi · GC-MS . Metabolite analysis · Tyrosol

\section{Introduction}

Zingiber officinale or ginger is an outstanding member among the 1400 species in the family Zingiberaceae (Le et al. 2014). Due to its unique flavor, it is a favorite spice across the globe. Ginger has been widely used in Ayurvedic, Chinese, and Tibb-Unani herbal formulations, since ancient times for treatment of unrelated ailments including indigestion, vomiting, constipation, dementia, hypertension, arthritis, rheumatism, pains, sprains, sore throat, cramps, fever, helminthiasis, and infectious diseases (Ali et al. 2008). India, also called 'the spice bowl of the world', is the largest producer of ginger. Ginger has rich cultivar diversity in India, which is generally named after localities, where they are grown. More than 50 cultivars possessing varying yield and quality are grown in India with its state Kerala having more diversity followed by northeastern states of India (Ravindran et al. 2005). Major cultivars grown in India are Himachal, Maran, Assam, China, Nadia, and the exotic cultivar Rio de Janerio. Several improved varieties of ginger have also been developed which are disease resistant and high yielding. The prominent varieties developed include Athira, Rajatha, Mahima, Suprabha, Suruchi, Suravi, Himagiri, Karthika, Varada, among many others (http://iisr.agropedias.iitk.ac.in/content/varietiesginger).

Being a herb of medicinal and culinary value, the ginger rhizomes are consumed raw. Microbiome of raw eaten vegetables and spices and the various bioactive metabolites produced by these microbes have been long ignored (Jackson et al. 2015). Endophytic fungi form a major group 
of plant microbiome, often assisting in plant growth and providing resistance against phytopathogens by the production of biologically active metabolites. These fungi live in the internal tissue of a healthy plant without apparently causing any harm to the plant. Endophytic fungi residing in ginger rhizomes and the metabolites produced by these fungi may have a possible role in the bioactivity of the ginger extracts, quality of the spice, as well can have effect on human health, as these are not removed by routine washing. These metabolites are often produced against host specific phytopathogens and may show a broad range of bioactivity which includes antibacterial, antifungal, cytotoxic, anticancerous, antioxidant, and antiinflammatory activity. Many metabolites are also found to possess plant growth promoting properties. Thus, these endophytes may also play a key role in the plant yield and disease resistance shown by improved varieties. In our previous studies, we had isolated 15 endophytic fungi from Athira (Anisha and Radhakrishnan 2015) and Mahima (unpublished data) varieties of ginger. Two isolates identified as Acremonium sp. and Paraconiothyrium sp. showed remarkable activity against ginger soft rot pathogen Pythium myriotylum and various clinical pathogens tested due to the production of gliotoxin and danthron, respectively. Both the metabolites identified showed a broad range of bioactivity. Thus, there is a need to study and understand the nature of endophytic fungi residing in the rhizomes of ginger in the context of both agriculture and human consumption of plant material. In the current study, we have identified the remaining endophytes and have tried to identify the bioactive metabolites produced by the isolates by metabolite analysis of fungal culture extracts using GC-MS.

\section{Materials and methods}

\section{Isolation and identification of endophytic fungi from different varieties of ginger}

Endophytic fungi were isolated from ginger variety Rio de Janerio and a Vellayanikkara variety, collected from Kerala Agricultural University, Thrissur, Kerala. The surface sterilization of rhizomes was done according to Schulz et al. (1993). Surface sterilized rhizomes were cut into small segments and incubated on Potato Dextrose Agar (PDA) media amended with $250 \mu \mathrm{g} / \mathrm{ml}$ streptomycin sulphate and was observed for any growth of fungi. Meanwhile, the last wash of surface sterilization was spread plated on PDA media and kept as control to check the sterility of surface sterilization procedure. For any growth on the surface sterility check plates, the experiment was repeated. The isolated fungi were further identified morphologically and by molecular methods. Previously isolated endophytic fungi from ginger varieties Athira and Mahima, collected from Kerala Agricultural University, were also identified and studied in the current work.

The endophytic fungal isolates were morphologically studied by slide culture technique. The slides stained with trypan blue were observed under $100 \times$ oil immersion. Images were processed using the $\mathrm{Q}$ imaging software. Molecular identification of the isolates was done by sequencing internal transcribed spacer (ITS) regions of the fungal genome. The genomic DNA was isolated using both Chromous Biotech gDNA minispin kit and by CTAB method (Voigt et al. 1999). ITS region of the fungal genome was Polymerase chain reaction (PCR) amplified using primers ITS1 (5'-TCC gTA ggT gAA CCT gCg g- $\left.3^{\prime}\right)$ and ITS4 (5'-TCC TCC gCT TAT TgA TAT gC-3') (White et al. 1990). PCR was done on Sure cycler 8800 (Agilent technologies) with the initial denaturation temperature of $95{ }^{\circ} \mathrm{C}$ for $5 \mathrm{~min}, 35$ cycles of denaturation at $94{ }^{\circ} \mathrm{C}$ for $1 \mathrm{~min}$, annealing at $55.5^{\circ} \mathrm{C}$ for $30 \mathrm{~s}$, extension for $2 \mathrm{~min}$ at $72{ }^{\circ} \mathrm{C}$, and with a final extension of $72{ }^{\circ} \mathrm{C}$ for $10 \mathrm{~min}$. Agarose gel electrophoresis was done to confirm the PCR products formed, which were then used as template for sequencing PCR using Big Dye Terminator Sequence Reaction Ready Mix (Applied Biosystems). ITS sequences obtained were analysed using Basic Local Alignment Search Tool (BLAST), to identify the most similar sequences from Genbank.

\section{Screening for activity against Pythium myriotylum}

Dual culture technique was done to screen the endophytic fungi for activity against $P$. myriotylum. Endophytic isolates were grown on PDA plates near to its edge for 7 days at room temperature. After growth of the endophyte, the phytopathogen, $P$. myriotylum was inoculated near to the opposite edge of the plate and was observed for its growth for 3-5 days. PDA plate with Pythium alone was kept as control. Percentage inhibition of fungal growth was calculated using the formulae: $\mathrm{PI}=\left(R_{1}-R_{2}\right) / R_{1} \times 100$, where $R_{1}$ and $R_{2}$ are the radial diameter of the phytopathogenic fungal colony in the control plate and dual culture plate, respectively (Rabha et al. 2014).

\section{Screening for activity against clinical pathogens}

To screen for activity against clinical pathogens, the endophytes were first grown in $250 \mathrm{ml}$ of Potato Dextrose Broth $(\mathrm{PDB})$, by inoculating an agar block $(0.5 \times 0.5 \mathrm{~cm})$ of actively growing fungi into PDB. The fungal cultures were then incubated at room temperature for 21 days following which it was filtered through four layers of cheese cloth and then with filter paper to obtain mycelia free filtrate. The clear filtrates were then extracted thrice with 
equal volume of ethyl acetate. Ethyl acetate extract was concentrated at $45{ }^{\circ} \mathrm{C}$ on a vacuum rotary evaporator. The final extract obtained was dissolved in $1 \mathrm{ml}$ methanol. The antibacterial activity of these extracts was checked against Bacillus subtilis (MTCC 121), Escherichia coli (MTCC 723), Klebsiella pneumoniae (MTCC 109), Staphylococcus aureus (MTCC 96), and Salmonella enterica typhimurium (MTCC 1251).

\section{Metabolite analysis of endophytic extracts for bioactive metabolites}

To identify bioactive metabolites produced by the endophytic fungi, the culture extracts were subjected to Gas Chromatography-Mass Spectrometry (GC-MS) analysis on an Agilent technologies-7890 GC system. To the GC system provided with $30 \mathrm{~m} \times 0.25 \mathrm{~mm}$ inner diameter, 0.25- $\mu \mathrm{m}$ film thickness Agilent 190913-433 column, $1 \mu \mathrm{l}$ of the sample was injected. GC oven was held at $100{ }^{\circ} \mathrm{C}$ and then ramped from 100 to $250{ }^{\circ} \mathrm{C}$ at $5{ }^{\circ} \mathrm{C} / \mathrm{min}$. The chromatogram and the mass spectra were recorded and analysed by comparing with the NIST library. Compounds identified were then literature searched for their biological activity.

\section{Results}

\section{Isolation and identification of endophytic fungi from different varieties of ginger}

Three endophytic fungal isolates (GFA1, GFA2, and GFA3) were obtained from the ginger variety Rio de Janerio and one isolate (GFV1) was obtained from Vellayanikkara variety. On molecular identification, the ITS sequence of GFA1 showed maximum similarity of $84 \%$ to Trichothecium sp., GFA2 was $82 \%$ identical to an uncultured fungus clone and GFA3 was $100 \%$ similar to $\mathrm{Col}$ letotrichum crassipes. Previously isolated endophytes from the variety Athira (GF1, GF2, GF4, GF6, and GF8) and Mahima (GFM2, GFM3, GFM5, GFM8, GFM10, GFM11, and GFM12) were also identified. Sequences of isolates GF1 and GF2 and also its morphology were found to be similar and were found to show $99 \%$ similarity to Ascomycota sp. on BLAST analysis. Its morphology was identified as that of Acremonium sp. Isolate GF4 showed 99\% similarity to Fusarium sp., whereas GF6 was $99 \%$ similar to Gliocladiopsis sp. and GF8 was $99 \%$ similar to Acremonium furcatum. Isolate GFM2 from Mahima showed $100 \%$ similarity to Aspergillus niger, and GFM3 was $99 \%$ similar to an uncultured fungal clone and also to Phlebia sp. Isolates GFM5 and GFM8 showed 100\% similarity to Fusarium oxysporum and $99 \%$ similarity to
Earliella scabrosa, respectively. ITS sequence of GFM10 was $82 \%$ similar to an uncultured fungal clone, while GFM11 was $99 \%$ similar to Pseudolagarobasidium sp. and GFM12 was $99 \%$ similar to an uncultured fungus clone. GFM3, GFM8, GFM11, and GFM12 were found to come under the phylum Basidiomycota. The ITS sequences obtained were submitted to the GenBank (Table 1). The fungal morphology and slide culture were also studied to draw-in conclusions regarding the identity of fungal isolates (Figs. 1, 2).

\section{Screening for bioactivity of endophytic fungi}

Seven isolates were found to show activity against $P$. myriotylum on dual culture. GF6 showed maximum inhibition of $71 \%$ followed by GFM3 (58\%), GFM12 (56\%), GFV1 (53.3\%), GFM2 (51.2\%), GFM5 (44\%), and GF4 $(36.6 \%)$. Antibacterial activity was shown only by two isolates, GFM5 and GFV1. The bioactivity exhibited by the endophytic isolates is summarized in Table 2.

\section{Metabolite analysis of endophytic extracts for bioactive compounds}

The GC-MS analysis of the fungal crude extracts of seven isolates revealed presence of bioactive volatile compounds (Table 3; Fig. 3). The isolates GFM12 and GFV1 were found to produce tyrosol. GFV1 also produced benzene acetic acid and dehydromevalonic lactone. Other compounds produced were ergone by GF6 and $\mathrm{N}$-aminopyrrolidine by GFM12. Among the isolates, six were found to produce bioactive fatty acids and its derivatives. Isolates GFA1, GFA2, GFM10, GFM11, GFM12, and GFV1 produced $n$-hexadecanoic acid. GFV1 produced myristic acid and methyl linoleate. Isolates GFM10 and GFV1 were found to produce palmitic acid methyl ester. GFM11, GFM12, and GFV1 produced linoleic acid, where as oleic acid production was exhibited by GFM12 and GFV1.

\section{Discussion}

Fifteen endophytic fungal isolates belonging to 14 different genera were identified in the study. Four isolates were identified from the variety Athira. An isolate previously identified in our study from Athira makes a total of five endophytic fungi from the variety. Seven isolates identified in the current study from the variety Mahima and one previously identified make a total of eight isolates from Mahima. Rio de Janerio and Vellayanikkara variety yielded three and one endophytes, respectively. Thus, the variety Mahima was found to harbor more diverse fungi followed by Athira. The morphological and molecular identification 
Table 1 Endophytic fungi from Z. officinale with their closest match as identified by BLAST analysis and the accession numbers of the partial ITS sequences of the endophytic isolates submitted to GenBank

\begin{tabular}{llrl}
\hline Endophytic fungi & Closest NCBI match & Percentage identity & $\begin{array}{l}\text { Submitted to NCBI with } \\
\text { accession no. }\end{array}$ \\
\hline GF1/GF2 & Ascomycota sp. & KX247110 \\
GF4 & Fusarium sp. & 99 & KX247111 \\
GF6 & Gliocladiopsis & 99 & KX247112 \\
GF8 & Acremonium furcatum & 99 & KX247113 \\
GFA1 & Trichothecium sp. & 99 & KX247122 \\
GFA2 & Uncultured fungus clone & 84 & KX247123 \\
GFA3 & Colletotrichum crassipes & 82 & KX247124 \\
GFM2 & Aspergillus niger & 100 & KX247114 \\
GFM3 & Uncultured fungus clone/Phlebia sp. & 100 & KX247115 \\
GFM5 & Fusarium oxysporum & 99 & KX247116 \\
GFM8 & Earliella scabrosa/uncultured fungus & 100 & KX247117 \\
GFM10 & Uncultured fungus clone & 99 & KX247118 \\
GFM11 & Pseudolagarobasidium sp. & 82 & KX247119 \\
GFM12 & Uncultured fungus clone/Cerrena sp. & 99 & KX247120 \\
GFV1 & Fungal sp. & 99 & KX247125 \\
\hline
\end{tabular}
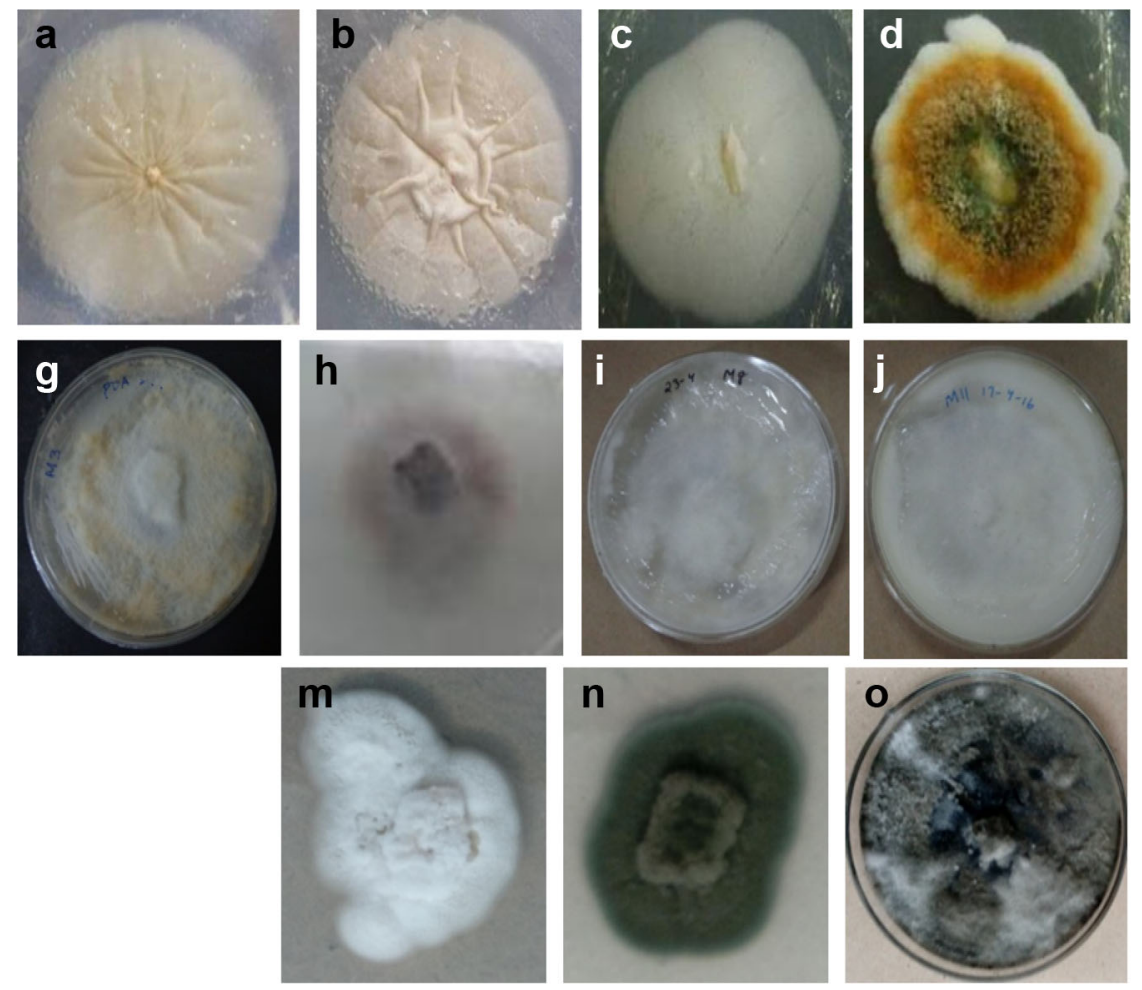
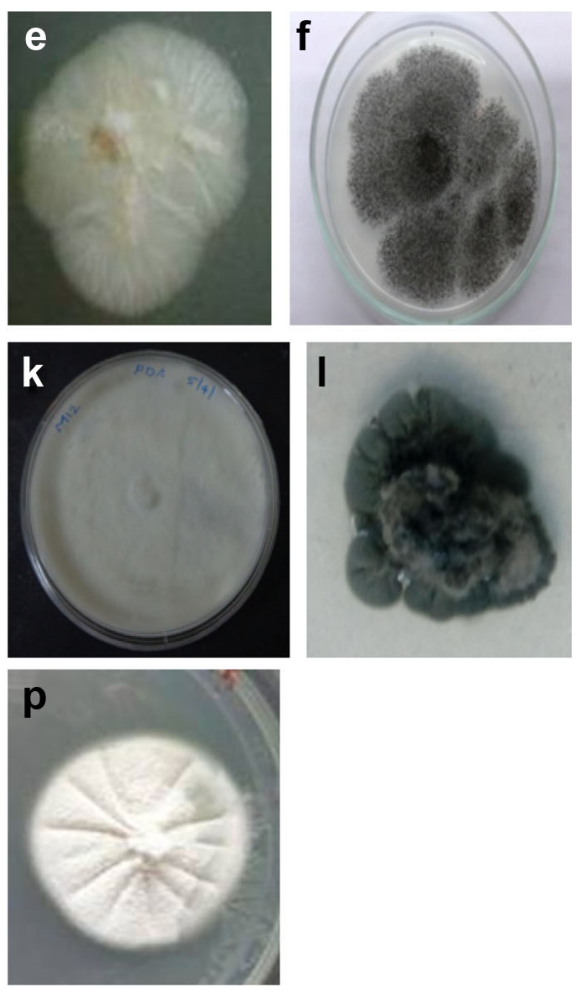

Fig. 1 Endophytic fungi from Z. officinale cultured on PDA plates: a GF1, b GF2, c GF4, d GF6, e GF8, f GFM2, g GFM3, h GFM5, i GFM8, j GFM11, k GFM12, 1 GFM10, m GFA1, n GFA2, o GFA3, and p GFV1

studies were coinciding. The different genera of fungi identified were Acremonium sp., Gliocladiopsis sp., Fusarium sp., Colletotrichum sp., Aspergillus sp., Phlebia sp., Earliella sp., and Psuedolagarobasidium sp. For some fungi, identification to the genus level was not possible. Though Ginting et al. (2013) had isolated and identified many endophytic fungi from different parts of red ginger from Indonesia, comprehensive work on the identification 

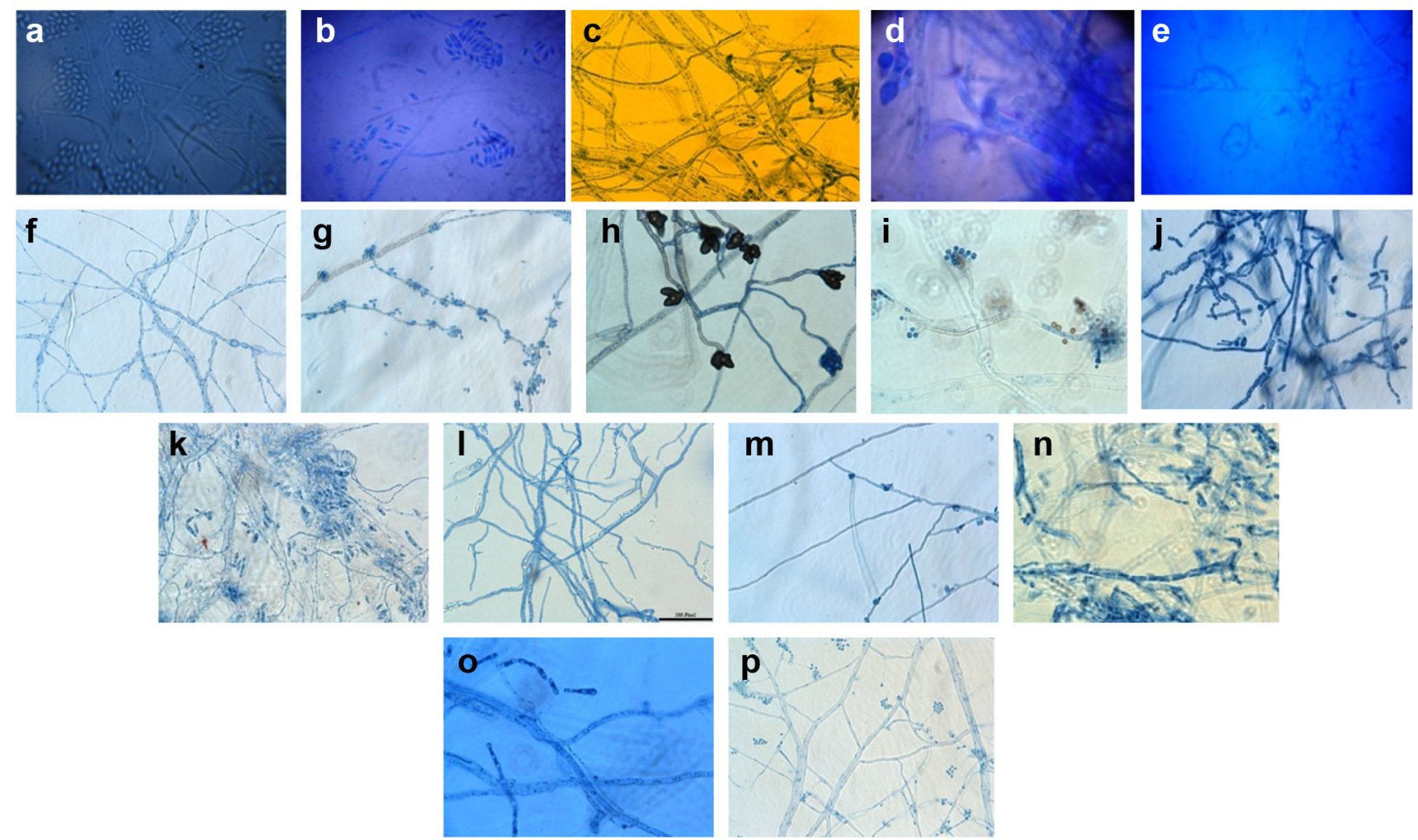

Fig. 2 Microscopic images of endophytic fungal slide cultures: a GF1, b GF2, c GF4, d GF6, e GF8, f GFA1, g GFA2, h GFA3, i GFM2, j GFM3, k GFM5, l GFM8, m GFM10, n GFM11, o GFM12, and p GFV1

Table 2 Percentage inhibition of Pythium and antibacterial activity [zone of inhibition (mm)] shown by the endophytic fungal extracts

\begin{tabular}{|c|c|c|c|c|c|c|}
\hline \multirow[t]{2}{*}{ Endophytic fungi } & \multirow{2}{*}{$\begin{array}{l}\text { P. myriotylum } \\
\text { (\% inhibition) }\end{array}$} & \multicolumn{5}{|c|}{ Zone of inhibition (mm) } \\
\hline & & S. aureus & B. subtilis & S. typhimurium & K. pneumoniae & E. coli \\
\hline GF2 & - & - & - & - & - & - \\
\hline GF4 & 36.66 & - & - & - & - & - \\
\hline GF6 & 71.11 & - & - & - & - & - \\
\hline GF8 & - & - & - & - & - & - \\
\hline GFA1 & - & - & - & - & - & - \\
\hline GFA2 & - & - & - & - & - & - \\
\hline GFA3 & - & - & - & - & - & - \\
\hline GFM2 & 51.22 & - & - & - & - & - \\
\hline GFM3 & 57.97 & - & & & & \\
\hline GFM5 & 44 & 14 & 18 & - & - & - \\
\hline GFM8 & - & - & - & - & - & - \\
\hline GFM10 & - & - & - & - & - & - \\
\hline GFM11 & - & - & - & - & - & - \\
\hline GFM12 & 56 & - & - & - & - & - \\
\hline GFV1 & 53.33 & 20 & 10 & 10 & - & - \\
\hline
\end{tabular}

of endophytic fungi from ginger grown in the Indian subcontinent has not been reported so far. In our previous work, we had identified a very potent Acremonium sp. from the ginger variety Athira which showed promising bioactivity. Thus, this genus may be concluded as the most frequently isolated fungi from the variety Athira. 
Table 3 Bioactive compounds in the endophytic fungal extracts as identified by GC-MS

\begin{tabular}{ll}
\hline Compound & $\begin{array}{l}\text { Endophytic fungi and the relative abundance of the } \\
\text { compound }\end{array}$ \\
\hline Dehydromevalonic lactone & GFV1 (3.64\%) \\
Benzene acetic acid & GFV1 (1.64\%) \\
Benzeneethanol, 4-hydroxy-(tyrosol) & GFV1 (3.39\%), GFM12 (0.16\%) \\
Tetradecanoic acid (myristic acid) & GFV1 (0.93\%) \\
Hexadecanoic acid & GFV1 (1.16\%), GFM10 (1.36\%) \\
Methyl ester (palmitic acid methyl ester) & GFV1 (1.75\%), GFM10 (3.10\%) \\
$n$-Hexadecanoic acid & GFV1 (18.65\%), GFM12 (13.44\%), GFM11 (26.06\%), \\
$9,12-$ Octadecadienoic acid (Z,Z)-, & GFA1 (8.54\%), GFA2 (26.11\%), GFM10 (18.45\%) \\
methyl ester (methyl linoleate) & GFV1 (0.89\%) \\
$9,12-$ Octadecadienoic acid (Z,Z) (linoleic & GFV1 (6.12\%), M12 (6.79\%), M11 (26.45\%) \\
acid) & GFV1 (13.24\%), M12 (60.68\%) \\
Oleic acid & GFM12 (0.14\%) \\
$N$-Aminopyrrolidine & GF6 (84.53\%) \\
Ergosta-4, 6, 8(14), 22-tetraen-3-one & \\
(ergone) &
\end{tabular}

Acremonium sp. are reported as major grass endophytes (White 1987) and also have wide occurence as endophytes in many non-grass plants such as Rhizophora apiculata (Rukachaisirikul et al. 2012), Vitis vinifera (Arnone et al. 2009), Actinidia macrosperma (Lu et al. 2012), Bursera simaruba (González et al. 2016), and many more. Gliocladiopsis sp. has been reported as endophyte from Paris polyphylla (Li et al. 2008) and Rafflesia cantleyi (Refaei et al. 2011). Fusarium sp. has a wide occurrence as endophyte in many plant species including Drepanocarpus lunatus (Liu et al. 2016), Axonopus compressus (Zakaria and Ning 2013), Nothapodytes foetida (Musavi and Balakrishnan 2013), Dioscorea zingiberensis (Li et al. 2014), Solanum lycopersicum (Aimé et al. 2013), Juniperus recurva, Catharanthus roseus (Kumar et al. 2013), Ginkgo biloba (Cui et al. 2012), etc. Colletotrichum sp. is another very frequently isolated endophyte and the isolate C. crassipes identified in the study has been reported from Artemisia sp. (Huang et al. 2009), Phyllanthus amarus (Kandasamy et al. 2015), and Tinospora cordifolia (Mishra et al. 2012). Aspergillus niger is reported as endophyte from Tabebuia argentea (Channabasava and Govindappa 2014), Heteroscyphus tener (Li et al. 2013), Avicennia marina (Liu et al. 2013), Opuntia dillenii (Ratnaweera et al. 2015), Entandrophragma congoense (Sandhu et al. 2014), and many more. The remaining genera identified including Phlebia sp., Earliella sp., and Pseudolagarobasidium sp. comes under the phylum Basidiomycota. Basidiomycetes, though reported as endophytes, are less studied (Martin et al. 2015) and are not very commonly isolated like Ascomycetes. This is the first report of members of Basidiomycota from ginger rhizomes. Phlebia sp. has been reported as endophyte from Piper hispidum (Orlandelli et al. 2012), Hevea (Martin et al. 2015), and Elaeis guineensis (Anuar et al. 2015). While Earliella scabrosa has been isolated from Pinus densiflora (Kil et al. 2009). Pseudolagarobasidium sp. as an endophyte is reported from Bruguiera gymnorrhiza (Wibowo et al. 2016).

In the bioactivity analysis of the endophytic fungi, seven isolates from the 15 identified (nearly 50\%) showed activity against $P$. myriotylum, but only two isolates showed antibacterial activity against clinical pathogens. Isolate GF6, identified as Gliocladiopsis sp., showed a significant inhibition of $P$. myriotylum followed by Phlebia sp. GFM3, uncultured fungus clone GFM12, Fungal sp. GFV1, Aspergillus sp. GFM2, Fusarium sp. GFM5, and Fusarium sp. GF4. Fungal sp. GFV1 and Fusarium sp. GFM5 were the isolates which showed activity against bacterial isolates. Crude extract of Gliocladiopsis sp. isolated from $R$. cantleyi is previously reported to inhibit the growth of Candida albicans (Refaei et al. 2011). Extracts of endophytic $A$. niger have also been reported to have activity against $C$. albicans (Ratnaweera et al. 2015). Aspergillus niger from Entandrophragma congoense produced a dimeric naphtho- $\gamma$-pyrone, 2-hydroxydihydronigerone along with nigerone, pyrophen, kojic acid, 4-(hydroxymethyl)-5-hydroxy-2H-pyran-2-one, and $p$-hydroxyphenylacetic acid. All the compounds exhibited weak antibacterial activity against gram-negative bacteria (Happi et al. 2015). Endophytic Aspergillus niger has also been reported as a good source of anticancer agents such as lapachol (Channabasava and Govindappa 2014), Malformin A1 (Li et al. 2013), lovastatin, and nigerasterols A 


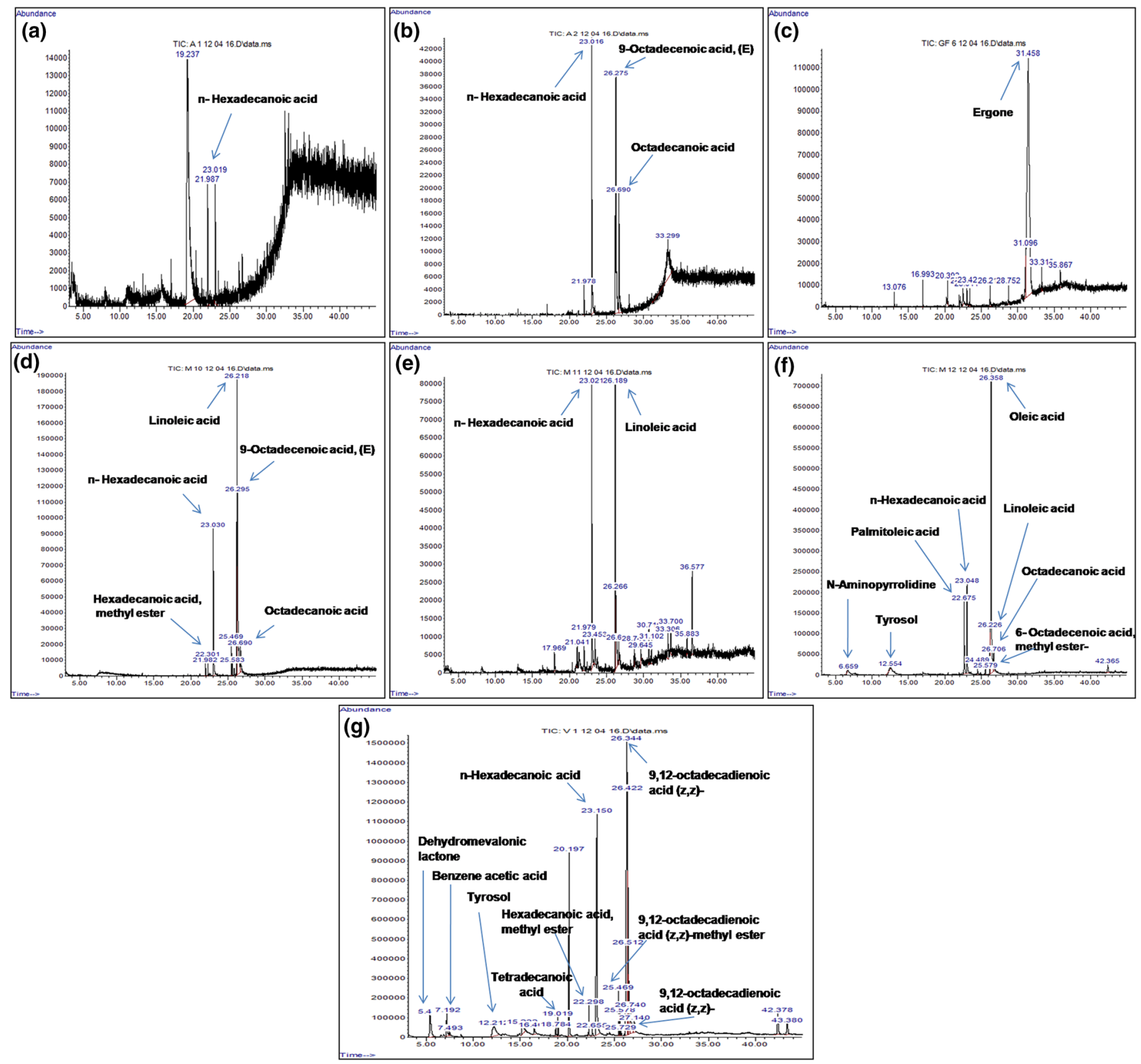

Fig. 3 Total ion chromatogram of endophytic fungal crude extracts showing the presence of bioactive compounds at various retention times: a GFA1, b GFA2, c GF6, d GFM10, e GFM11, f GFM12, and g GFV1

and B (Liu et al. 2013). Crude extract of endophytic $F$. oxysporum has been reported to have activity against $C$. albicans and various bacterial isolates tested (Musavi and Balakrishnan 2013). Endophytic $F$. oxysporum is also reported to produce its corresponding host metabolites such as podophyllotoxin, taxol (Elavarasi et al. 2012), ginkgolide B (Cui et al. 2012), vincristine, and vinblastin (Kumar et al. 2013), which thus indicates its close association with different hosts.

In the GC-MS analysis of endophytic crude extracts, tyrosol production was observed in the Fungal sp. GFV1 and GFM12. Tyrosol has previously been reported in endophytic culture extracts of Diaporthe (Specian et al. 2012), Colletotrichum (Bungihan et al. 2013), Glomerella (Guimarães et al. 2009), Phyllosticta (Tan et al. 2015), and Phialocephala fortinii (Cui et al. 2016). It has a wide range of bioactivity including plant growth promotion (Kimura and Tamura 1973), cytotoxicity (Guimarães et al. 2009), antibacterial, and antifungal (Specian et al. 2012; Brilhante et al. 2016), and is a very potent antioxidant. Interestingly, it is also the quorum sensing molecule involved in the morphogenesis of the dimorphic fungi $C$. albicans (Wongsuk et al. 2016). N-Aminopyrrolidine was also detected in the crude extract of GFM12. Benzene acetic 
acid and dehydromevalonic lactone were two other compounds detected in Fungal sp. GFV1. Benzene acetic acid has been reported from the endophytic fungus Chaetomium fusiforme (Guo et al. 2008). It is a type of auxin (Wightman and Lighty 1982) and is an antimicrobial produced by metapleural glands of most ant species for controlling fungal pathogens (Fernandez-Marin et al. 2015). Dehydromevalonic lactone has been reported to be produced during the solid-state fermentation of Monascus ruber, and is reported to impart fragrance (Vidyalakshmi et al. 2009). The isolate Gliocladiopsis sp. GF6, which was most bioactive against Pythium, was found to produce Ergosta-4, 6, 8(14), 22-tetraen-3-one also called ergone. Ergone is a cytotoxic metabolite reported from mushrooms including Polyporus umbellatus (Lee et al. 2005) and Ganoderma atrum (Shen et al. 2008). It is also reported to show antialdosteronic diuretic effect (Yuan et al. 2004). Other major group of biological compound detected in many of the endophytic crude extracts was fatty acids and their derivatives. Fatty acids and their derivatives are major metabolites of many fungi including Basidiomycetes (Sumner 1973). They have been reported to possess antibacterial (Kabara et al. 1972), antifungal (Walters et al. 2004), antimalarial (Carballeira 2008), and antinematicidal activities (Stadler et al. 1994). The underlying mechanism proposed for the bioactivity of fatty acids is their ability to disrupt cell membrane (Bergsson et al. 2001). This may in turn increase the intake of other antimicrobials into the cytoplasm of pathogens.

In the current study, the highest activity against Pythium was exhibited by the ergone producing Gliocladiopsis sp. GF6 isolated from the variety, Athira. Acremonium sp., isolated in our previous study, displayed a strong antagonism to Pythium by the production of gliotoxin and was an endophyte isolated from the variety Athira. In addition, we had previously isolated a very potent endophytic bacterium from this variety which showed high activity against Pythium due to the production of phenazine (Jasim et al. 2014). Ginger variety Athira, developed from the cultivar Maran, is specifically tolerant to soft rot caused by Pythium sp. and to bacterial wilt than its parent cultivar and other varieties. The one possible reason for this may be attributed to the presence of these bioactive endophytes in the ginger rhizome. More than $60 \%$ of the isolates from variety Mahima, including previously identified Paraconiothyrium sp., showed activity against Pythium. Mahima is a high yielding variety of ginger resistant to nematodes Meloidogyne incognita and M. javanica. It is interesting to note that basidiomycetes formed a major group of endophytes isolated from this variety, and two of them Phlebia sp. and GFM12 showed activity against Pythium. GFM12, Pseudolagarobasidium sp., and Fungal sp. GFM10 from Mahima and Fungal sp. GFV1 from Vellayanikkara variety were found to produce linoliec acid which has been reported to have excellent nematicidal activity (Stadler et al. 1994). Linoliec acid is the most abundantly produced fatty acid by Basidiomycetes (Sumner 1973). Endophytic production of fatty acids probably can play a role in resistance of the variety Mahima against nematodes. The population of endophytic fungi in all varieties studied varied, which may be due to difference in the genotype of the plant or environmental conditions. The endophytes may thus be a contributing factor in the differences in the performance of various varieties of ginger.

Thus, the myriad of endophytic fungi living in ginger rhizomes and the metabolites produced by them can impart a synergistic effect on the pathogens of ginger. An understanding of these metabolites is essential in the context of consumption of ginger as a medicine and spice.

Acknowledgements This work was financially supported by the Department of Science and Technology, Government of India under DST-PURSE program (Order No: SR/S9/Z-23/2010/22). We are thankful to Kerala State Council Science Technology and Environment (KSCSTE) for providing facilities under KSCSTE-SARD program. The authors acknowledge the Department of Biotechnology (DBT), Government of India for the instrumentation facility provided under DBT-RGYI and DBT-MSUB support scheme. We are grateful to the Department of Applied Chemistry, Cochin University of Science and Technology for the help and support for GC-MS analysis. We also acknowledge Kerala Agricultural University, Thrissur, Kerala, for providing the ginger samples.

\section{Compliance with ethical standards}

Conflict of interest The authors declare that they have no conflict of interest.

\section{References}

Aimé S, Alabouvette C, Steinberg C, Olivai C (2013) The endophytic strain Fusarium oxysporum Fo47: a good candidate for priming the defense responses in tomato roots. Mol Plant Microbe Interact 26(8):918-926

Ali BH, Blunden G, Tanira MO, Nemmar A (2008) Some phytochemical, pharmacological and toxicological properties of ginger (Zingiber officinale Roscoe): a review of recent research. Food Chem Toxicol 46:409-420

Anisha C, Radhakrishnan EK (2015) Gliotoxin-producing endophytic Acremonium sp. from Zingiber officinale found antagonistic to soft rot pathogen Pythium myriotylum. Appl Biochem Biotechnol 175:3458-3467

Anuar EN, Nulit R, Idris AS (2015) Growth promoting effects of endophytic fungus Phlebia GanoEF3 on oil palm (Elaeis guineensis) seedlings. Int J Agric Biol 17:135-141

Arnone A, Assante G, Bava A, Dallavalle S, Nasini G (2009) Acremines $\mathrm{H}-\mathrm{N}$, novel prenylated polyketide metabolites produced by a strain of Acremonium byssoidesq. Tetrahedron 65:786-791

Bergsson G, Arnfinnsson JH, Steingrímsson O, Thormar H (2001) In vitro killing of Candida albicans by fatty acids and monoglycerides. Antimicrob Agents Chemother 45(11):3209-3212 
Brilhante RSN, Caetanoa EP, de Limaa RAC et al (2016) Terpinen-4-ol, tyrosol, and $\beta$-lapachone as potential antifungals against dimorphic fungi. Braz J Microbiol. doi:10.1016/j.bjm.2016.07.015

Bungihan ME, Tan MA, Takayama H, dela Cruz TEE, Nonato MG (2013) A new macrolide isolated from the endophytic fungus Colletotrichum sp. Philipp Sci Lett 6(1):57-73

Carballeira NM (2008) New advances in fatty acids as antimalarial, antimycobacterial and antifungal agents. Prog Lipid Res 47(1):50-61

Channabasava R, Govindappa M (2014) First report of anticancer agent, lapachol producing endophyte, Aspergillus niger of Tabebuia argentea and its in vitro cytotoxicity assays. Bangladesh J Pharmacol 9:129-139

Cui Y, Yi D, Bai X, Sun B, Zhao Y, Zhang Y (2012) Ginkgolide B produced endophytic fungus (Fusarium oxysporum) isolated from Ginkgo biloba. Fitoterapia 5:913-920

Cui J, Guo T, Chao J, Wang M, Wang J (2016) Potential of the endophytic fungus Phialocephala fortinii Rac56 found in Rhodiola plants to produce salidroside and $p$-tyrosol. Molecules 21(4):502. doi:10.3390/molecules21040502

Elavarasi A, Rathna GS, Kalaiselvam M (2012) Taxol producing mangrove endophytic fungi Fusarium oxysporum from Rhizophora annamalayana. Asain Pac J Trop 2(2):S1081-S1085

Fernandez-Marın H, Nash DR, Higginbotham S, Estrada C, van Zweden JS, d'Ettorre P, Wcislo WT, Boomsma JJ (2015) Functional role of phenylacetic acid from metapleural gland secretions in controlling fungal pathogens in evolutionarily derived leaf-cutting ants. Proc R Soc B 282:20150212. doi:10. 1098/rspb.2015.0212

Ginting RCB, Sukarno N, Widyastuti U, Darusman LK, Kanaya S (2013) Diversity of endophytic fungi from red ginger (Zingiber officinale Rosc.) plant and their inhibitory effect to Fusarium oxysporum plant pathogenic fungi. HAYATI. J Biosci 20(3):127-137

González MC, Glenn AE, Hanlin RT, Rubalcava MLM, Bautista BEH, Anaya AL (2016) Acremonium camptosporum isolated as an endophyte of Bursera simaruba from Yucatan Peninsula, Mexico. Mycotaxon 131(1):211-225

Guimarães DO, Borges KB, Bonatob PS, Pupo MT (2009) A simple method for the quantitative analysis of tyrosol by hplc in liquid czapek cultures from endophytic fungi. J Braz Chem Soc 20(1):188-194

Guo L, Wu JZ, Han T, Cao T, Rahman K, Qin LP (2008) Chemical composition, antifungal and antitumor properties of ether extracts of Scapania verrucosa Heeg. and its endophytic fungus Chaetomium fusiforme. Molecules 13:2114-2125

http://iisr.agropedias.iitk.ac.in/content/varieties-ginger. Accessed 23 Aug 2016

Happi GM, Kouam SF, Talontsi FM, Nkenfou CN, Longo F, Zuehlke S, Douanla-Meli C, Spiteller M (2015) A new dimeric naphtho$\gamma$-pyrone from an endophytic fungus Aspergillus niger AKRN associated with the roots of Entandrophragma congoense collected in Cameroon. Z Naturforsch 70(9):625-630

Huang WY, Cai YZ, Surveswaran S, Hyde KD, Corke H, Sun M (2009) Molecular phylogenetic identification of endophytic fungi isolated from three Artemisia species. Fungal Divers 36:69-88

Jackson CR, Stone BWG, Tyler HL (2015) Emerging perspectives on the natural microbiome of fresh produce vegetables. Agriculture 5:170-187

Jasim B, Anisha C, Rohini S, Kurian JM, Jyothis M, Radhakrishnan EK (2014) Phenazine carboxylic acid production and rhizome protective effect of endophytic Pseudomonas aeruginosa isolated from Zingiber officinale. World J Microbiol Biotechnol 30(5):1649-1654

Kabara JJ, Swieczkowski DM, Conley AJ, Truant JP (1972) Fatty acids and derivatives as antimicrobial agents. Antimicrob Agents Chemother 2(1):23-28
Kandasamy P, Manogaran S, Dhakshinamoorthy M, Kannan KP (2015) Evaluation of antioxidant and antibacterial activities of endophytic fungi isolated from Bauhinia racemosa Lam and Phyllanthus amarus Schum and Thonn. J Chem Pharm Res 7(9):366-379

Kil YJ, Eo JK, Eom AH (2009) Molecular identification and diversity of endophytic fungi isolated from Pinus densiflora in Boeun, Korea. Korean J Mycol 37(2):130-133

Kimura Y, Tamura S (1973) Isolation of 1- $\beta$-phenyllactic acid and tyrosol as plant growth regulators from Gloeosporium laeticolor. Agric Biol Chem 37(12):2925

Kumar A, Patil D, Rajamohanan PR, Ahmad A (2013) Isolation, purification and characterization of vinblastine and vincristine from endophytic fungus Fusarium oxysporum isolated from Catharanthus roseus. PLoS One 8(9):e71805. doi:10.1371/ journal.pone.0071805

Le DP, Smith M, Hudler GW, Aitken E (2014) Pythium soft rot of ginger: detection and identification of the causal pathogens, and their control. Crop Prot 65:153e167

Lee WY, Park Y, Ahn JK, Park SY, Lee HJ (2005) Cytotoxic activity of Ergosta-4, 6, 8(14), 22-tetraen-3-one from the sclerotia of Polyporus umbellatus. Bull Korean Chem 26(9):1464-1466

Li J, Zhao J, Xu L, Zhou L, Li X, Wang J (2008) Endophytic fungi from rhizomes of Paris polyphylla var. Yunnanensis. World J Microbiol Biotechnol 24:733-737

Li XB, Xie F, Liu S, Li Y, Zhou JC, Liu YQ, Yuan HQ, Lou HX (2013) Naphtho- $\gamma$-pyrones from endophyte Aspergillus niger occurring in the liverwort Heteroscyphus tener (Steph.) Schiffn. Chem Biodivers 10:1193-1201

Li P, Luo H, Meng J, Sun W, Wang X, Lu S, Peng Y, Zhou L (2014) Effects of oligosaccharides from endophytic Fusarium oxysporum Dzf17 on activities of defense-related enzymes in Dioscorea zingiberensis suspension cell and seedling cultures. Electron $\mathrm{J}$ Biotechnol 17:156-161

Liu D, Li XM, Li CS, Wang BG (2013) Nigerasterols A and B, antiproliferative sterols from the mangrove-derived endophytic fungus Aspergillus niger MA-132. Helv Chim Acta 96:1055-1061

Liu S, Dai H, Orfali RS, Lin W, Liu Z, Proksch P (2016) New fusaric acid derivatives from the endophytic fungus Fusarium oxysporum and their phytotoxicity to barley leaves. J Agric Food Chem 64:3127-3132

Lu Y, Chen C, Chen H, Zhang J, Chen W (2012) Isolation and identification of endophytic fungi from Actinidia macrosperma and investigation of their bioactivities. Evid Based Complement Altern Med. doi:10.1155/2012/382742

Martin R, Gazis R, Skaltsas D, Chaverri P, Hibbett D (2015) Unexpected diversity of basidiomycetous endophytes in sapwood and leaves of Hevea. Mycologia 107(2):284-297

Mishra A, Gond SK, Kumar A, Sharma VK, Verma SK, Kharwar RN, Sieber TN (2012) Season and tissue type affect fungal endophyte communities of the Indian medicinal plant Tinospora cordifolia more strongly than geographic location. Microb Ecol 64:388-398

Musavi SF, Balakrishnan RJ (2013) Biodiversity, antimicrobial potential, and phylogenetic placement of an endophytic Fusarium oxysporum NFX 06 isolated from Nothapodytes foetida. J Mycol. doi:10.1155/2013/172056

Orlandelli RC, Alberto RN, Filho CJR, Pamphile JA (2012) Diversity of endophytic fungal community associated with Piper hispidum (Piperaceae) leaves. Gent Mol Res 11(2):1575-1585

Rabha AJ, Naglot A, Sharma GD, Gogoi HK, Veer V (2014) In vitro evaluation of antagonism of endophytic Colletotrichum gloeosporioides against potent fungal pathogens of Camellia sinensis. Indian J Microbiol 54(3):302-309

Ratnaweera PB, de Silva ED, Williams DE, Andersen RJ (2015) Antimicrobial activities of endophytic fungi obtained from the 
arid zone invasive plant Opuntia dillenii and the isolation of equisetin, from endophytic Fusarium sp. BMC Complement Altern Med 15:220

Ravindran PN, Babu KN, Shiva KN (2005) Botany and crop improvement of Ginger. In: Ravindran PN, Babu KN (eds) Ginger the genus Zingiber, vol 41. Book series: Medicinal and aromatic plants-industrial profiles. CRC Press, Florida, pp 15-85

Refaei J, Jones EBG, Sakayaroj J, Santhanam J (2011) Endophytic fungi from Rafflesia cantleyi: species diversity and antimicrobial activity. Mycosphere 2(4): 429-447

Rukachaisirikul V, Rodglin A, Sukpondma Y, Phongpaichit S, Buatong J, Sakayaro J (2012) Phthalide and isocoumarin derivatives produced by an Acremonium sp. isolated from a mangrove Rhizophora apiculata. J Nat Prod 75:853-858

Sandhu SS, Kumar S, Aharwal RP (2014) Isolation and identification of endophytic fungi from Ricinus communis linn. and their antibacterial activity. Int J Res Pharm Chem 4(3):611-618

Schulz B, Wanke U, Draeger S, Aust H (1993) Endophytes from herbaceous plants and shrubs: effectiveness of surface sterilization methods. Mycol Res 97:1447-1450

Shen M, Xie M, Nie S, Wang Y, Chen J, Li C, Li J (2008) Separation and identification of Ergosta-4, 6, 8(14), 22-tetraen-3-one from Ganoderma atrum by high-speed counter-current chromatography and spectroscopic methods. Chromatographia 67:999-1001

Specian V, Sarragiotto MH, Pamphile JA, Clemente E (2012) Chemical characterization of bioactive compounds from the endophytic fungus Diaporthe helianthi isolated from Luehea divaricata. Braz J Microbiol 43(3):1174-1182

Stadler M, Mayer A, Anke H, Sterner O (1994) Fatty acids and other compounds with nematicidal activity from cultures of Basidiomycetes. Planta Med 60(2):128-132

Sumner JL (1973) The fatty acid composition of basidiomycetes. N Z J Bot 11(3):435-442

Tan MA, dela Cruz TEE, Apurillo CCS, Proksch P (2015) Chemical constituents from a Philippine mangrove endophytic fungi Phyllosticta sp. Der Pharma Chemica 7(2):43-45
Vidyalakshmi R, Paranthaman R, Murugesh S, Singaravadivel K (2009) Microbial bioconversion of rice broken to food grade pigments. Glob J Biotechnol Biochem 4(2):84-87

Voigt K, Cigelnik E, O’Donnell K (1999) Phylogeny and PCR identification of clinically important Zygomycetes based on nuclearribosomal-DNA sequence data. J Clin Microbiol 37:3957-3964

Walters D, Raynor L, Mitchell A, Walker R, Walker K (2004) Antifungal activities of four fatty acids against plant pathogenic fungi. Mycopathologia 157(1):87-90

White JF (1987) Widespread distribution of endophytes in the Poaceae. Plant Dis 71:340-342

White TJ, Bruns T, Lee S, Taylor J (1990) Amplification and direct sequencing of fungal ribosomal RNA genes for phylogenetics. In: Innis MA, Gelfand DH, Sninsky JJ, White TJ (eds) PCR protocols: a guide to methods and applications. Academic Press, New York, pp 315-322

Wibowo M, Prachyawarakorn V, Aree T, Mahidol C, Ruchirawat S, Kittakoop P (2016) Cytotoxic sesquiterpenes from the endophytic fungus Pseudolagarobasidium acaciicola. Phytochemistry $122: 126-138$

Wightman F, Lighty DL (1982) Identification of phenylacetic acid as a natural auxin in the shoots of higher plants. Physiol Plant 55(1):17-24

Wongsuk T, Pumeesat P, Luplertlop N (2016) Fungal quorum sensing molecules: role in fungal morphogenesis and pathogenicity. J Basic Microbiol 56:440-447

Yuan D, Mori J, Komatsu K, Makino T, Kano Y (2004) An antialdosteronic diuretic component (drain dampness) in Polyporus sclerotium. Biol Pharm Bull 27(6):867-870

Zakaria L, Ning CH (2013) Endophytic Fusarium spp. from roots of lawn grass (Axonopus compressus). Trop Life Sci Res 24(2):85-90 